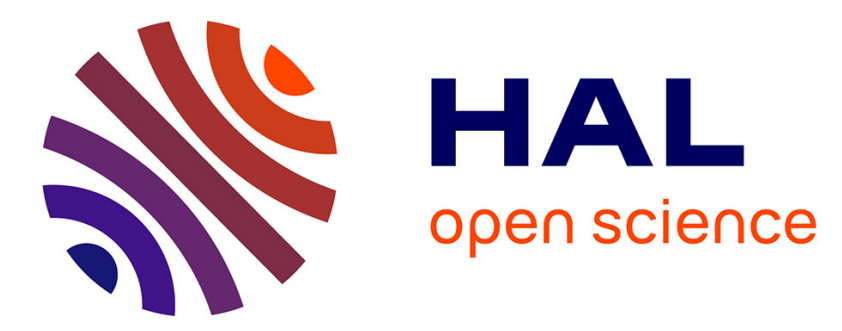

\title{
How spatial variability of initial porosity and fines content affects internal erosion in soils
}

\author{
Jie Yang, Zhen-Yu Yin, Pierre-Yves Hicher, Farid Laouafa
}

\section{To cite this version:}

Jie Yang, Zhen-Yu Yin, Pierre-Yves Hicher, Farid Laouafa. How spatial variability of initial porosity and fines content affects internal erosion in soils. China-Europe Conference on Geotechnical Engineering, Aug 2018, Vienna, Austria. pp.439-443, 10.1007/978-3-319-97112-4_99 . ineris-03239662

\section{HAL Id: ineris-03239662}

\section{https://hal-ineris.archives-ouvertes.fr/ineris-03239662}

Submitted on 27 May 2021

HAL is a multi-disciplinary open access archive for the deposit and dissemination of scientific research documents, whether they are published or not. The documents may come from teaching and research institutions in France or abroad, or from public or private research centers.
L'archive ouverte pluridisciplinaire HAL, est destinée au dépôt et à la diffusion de documents scientifiques de niveau recherche, publiés ou non, émanant des établissements d'enseignement et de recherche français ou étrangers, des laboratoires publics ou privés. 


\title{
How Spatial Variability of Initial Porosity and Fines Content Affects Internal Erosion in Soils
}

\author{
Jie Yang ${ }^{1,2}$, Zhen-Yu Yin ${ }^{2,3(\bowtie)}$, Pierre-Yves Hicher ${ }^{2}$, \\ and Farid Laouafa ${ }^{1}$ \\ 1 INERIS, 60550 Verneuil en Halatte, France \\ 2 Research Institute of Civil Engineering and Mechanics (GeM), \\ UMR CNRS 6183, Ecole Centrale de Nantes, 44300 Nantes, France \\ zhenyu.yin@ec-nantes.fr \\ ${ }^{3}$ Department of Civil and Environmental Engineering, The Hong Kong \\ Polytechnic University, Hung Hom, Kowloon, Hong Kong, China
}

\section{Introduction}

Internal erosion occurs when fines are pulled off by seepage forces and transported throughout the matrix of soil particles [1], which results in the degradation of soil strength [2-4]. This phenomenon has been widely studied experimentally and numerically over the last few decades [5-9]. In fact, soil nature is highly variable in space and then heterogenous in magnitude [10]. At the present time, few studies have been conducted to analyze the influence of variations of soil initial state (i.e. the initial porosity and the initial fraction of fines content) on the internal erosion behaviors. In this paper, a thermodynamically consistent continuum model of internal erosion is combined with the random field theory to investigate the erosion behavior of soil with spatially variable initial state of soil in one-dimensional condition.

\section{Mathematic Model of Internal Erosion}

The saturated porous medium is modelled as a material system composed of 4 constituents [11]: the stable fabric of the solid skeleton, the erodible fines, the fluidized particles and the pure fluid phase. The fines can behave either as a fluid-like (described as fluidized particles) or as a solid-like (described as erodible fines) material. Thus, a liquid-solid phase transition process has been accounted for in the present model by the introduction of a mass production term in the corresponding mass balances for erodible fines and fluidized particles. 
A system of the mass balance equations is then given by the following expressions:

$$
\begin{gathered}
-\partial_{t} \phi+\operatorname{div}\left(\mathbf{v}_{s}\right)-\operatorname{div}\left(\phi \mathbf{v}_{s}\right)=\hat{n} \\
\partial_{t}\left(f_{c}\right)-\partial_{t}\left(f_{c} \phi\right)+\operatorname{div}\left(f_{c} \mathbf{v}_{s}\right)-\operatorname{div}\left(f_{c} \phi \mathbf{v}_{s}\right)=\hat{n} \\
\partial_{t}(c \phi)+\operatorname{div}\left(c \mathbf{q}_{\mathbf{w}}\right)+\partial_{t}\left(c \phi \mathbf{v}_{s}\right)=-\hat{n} \\
\operatorname{div}\left(\mathbf{q}_{w}\right)+\operatorname{div}\left(\mathbf{v}_{s}\right)=0
\end{gathered}
$$

In which $\left\{\phi, f_{c}, c, \mathbf{q}_{w}\right\}$ denote the porosity, the fraction of erodible fines content, the concentration of fluidized particles and the total discharge of liquid; $\mathbf{v}_{s}$ denotes velocity of the soil skeleton deformation; $\hat{n}$ is the source term describing the exchange between the erodible fines and the fluidized particles.

$$
\hat{n}=\hat{n}_{e}+\hat{n}_{f}
$$

A model for the rate of the eroded mass $\hat{n}_{e}$ is given by the following relation [12]:

$$
\hat{n}_{e}=-\lambda_{e}(1-\phi)\left(f_{c}-f_{c \infty}\right)\left|\mathbf{q}_{\mathbf{w}}\right|
$$

where $\lambda_{e}$ is the material parameter, $f_{c \infty}$ is the maximum fines content fraction after long seepage time, assumed to be decreased with the increase in the hydraulic gradient [13]:

$$
f_{c \infty}=f_{c 0}\left[\left(1-\alpha_{1}\right) \exp \left(-\alpha_{2}\left|\mathbf{q}_{\mathbf{w}}\right|\right)+\alpha_{1}\right]
$$

The rate of the filtration is proposed as:

$$
\hat{n}_{f}=\lambda_{f} \frac{\phi-\phi_{\min }}{\phi^{\beta}} c\left|\mathbf{q}_{\mathbf{w}}\right|
$$

where $\lambda_{f}$ and $\beta$ are the material parameters, $\phi_{\min }$ is the minimum porosity of soil.

In this study, the flow in the porous medium is governed by Darcy's law:

$$
\mathbf{q}_{\mathbf{w}}=-\frac{k(\phi)}{\eta_{k} \bar{\rho}(c)}\left(\operatorname{grad}\left(p_{w}\right)-\bar{\rho}(c) \mathbf{g}\right)
$$

where $k$ denotes the intrinsic permeability of the medium (unit: $\mathrm{m}^{2}$ ), $\eta_{k}$ is the kinematic viscosity of the fluid (unit: $\mathrm{m}^{2} \mathrm{~s}^{-1}$ ), $p_{w}$ is the pore fluid pressure, $\mathbf{g}$ is the vector of the gravity field, and $\bar{\rho}$ is the density of the mixture defined as:

$$
\bar{\rho}=c \rho_{s}+(1-c) \rho_{f}
$$


The intrinsic permeability $k$ of the porous medium depends on the current porosity and fines content fraction. In our works we take the following expression [14]:

$$
k=\frac{k_{0}}{\left[1-f_{c 0}\left(1-\phi_{0}\right)\right]^{3 m}}\left[1-f_{c}(1-\phi)\right]^{3 m}
$$

where $m$ is the permeability parameter.

The mathematic model for a 1D internal erosion has been solved using a finite difference scheme. The computations of the following sections were carried out with $\Delta z=0.004 \mathrm{~m}$ (100 nodes) and $\Delta t=1.0 \mathrm{~s}$ to make sure the accuracy and convergence.

\section{Probabilistic Analysis}

The initial porosity $\phi_{0}$ and the initial fraction of fines content $f_{c 0}$ are assumed to be lognormally distributed random variables. They are generated by the local average subdivision method which fully takes into account the spatial correlation, local averaging, and cross correlation. The generated random variables are mapped onto a finitedifference mesh and numerical simulations based on Monte Carlo method are performed.

The following parameters for both $\phi_{0}$ and $f_{c 0}$ have been used for the probabilistic analysis in this study: (1) coefficient of variation $v: 0.05,0.075,0.1,0.125,0.15$ and 0.175 ; (2) relative correlation length $\Theta=\theta / L$ : $0.25,0.5,1.0,2.0$ and 4.0; (3) cross correlation coefficient $\rho$ between $\phi_{0}$ and $f_{c 0}$ : -1.0 and 1.0.

To keep accuracy and run-time efficiency, the sensitivity of results to the number of Monte Carlo simulations was examined. The results show that 2000 simulations are enough to give reliable and reproducible estimates.

Figure 1 compares the probability of blockage during erosion with different uncertainties of $\phi_{0}$ and $f_{c 0}$. The probability of blockage during erosion is defined by counting the number of simulations in which the calculated hydraulic conductivity is smaller than its initial value, and then divided by the total number of simulations.

The results indicate that increasing the uncertainty in $\phi_{0}$ and $f_{c 0}$ will always increases the probability of blockage during erosion. This can be explained by the fact that greater uncertainty leads to more dramatic changes in soil porosity and permeability at the interface of different layers, which in turn promotes the capture of the fine particles transported in water flow. Moreover, the ragged distributed $\phi_{0}$ and $f_{c 0}$ with lower spatial correlation lengths make the layered system more inconsistent, and it therefor accelerates the formation of the filter cakes at the interface. 

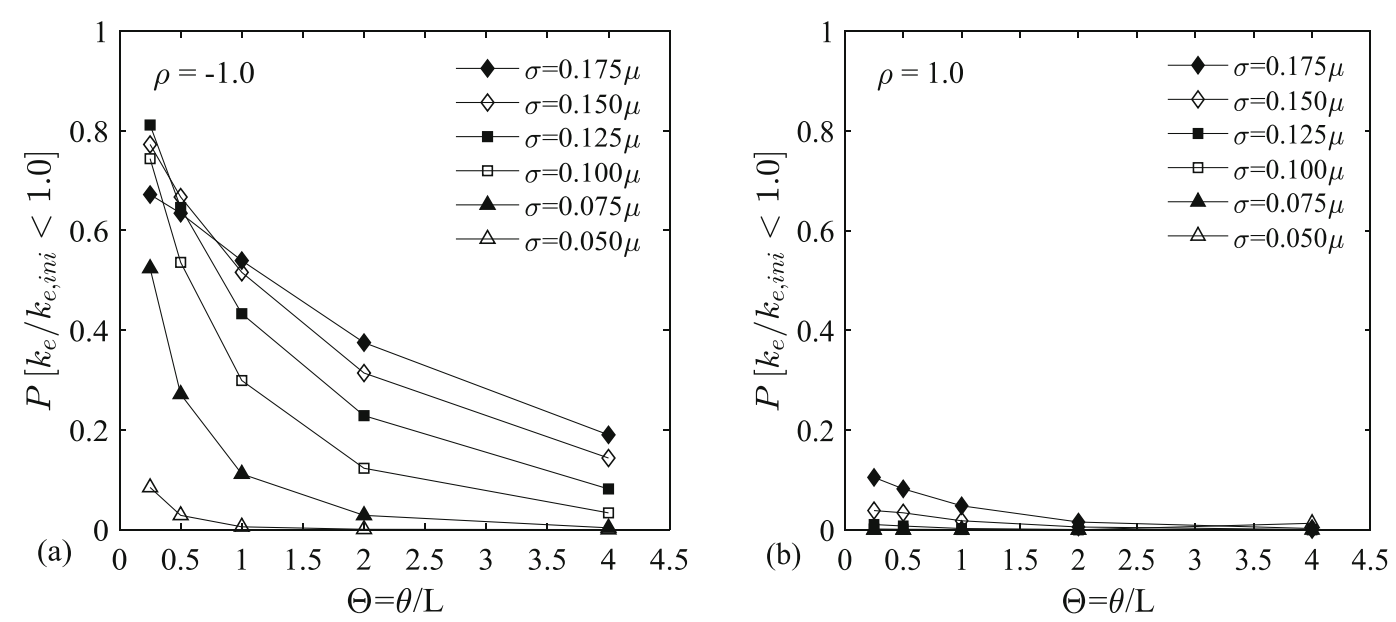

Fig. 1. 1D probabilistic results, comparison of probability of the appearance of blockage during erosion simulations: (a) $\rho=-1.0$; (b) $\rho=1.0$

\section{Conclusions}

The influence of the initial state of soil characterized by its porosity and fine content, on the suffusion and filtration behaviors during internal erosion process was investigated in this study. Probabilistic analysis shows that greater uncertainty leads to more dramatic changes of soil porosity and the permeability at the interface of different layers, which in turn promotes the capture of the fine particles transported in water flow. Higher spatial correlation length makes the layered system more uniform. However, the ragged distributed $\phi_{0}$ and $f_{c 0}$ with lower spatial correlation lengths make the layered system more inconsistent. It leads to a rougher transition between the high erodible zones and the low erodible zones and therefor accelerates the formation of the filter cakes at the interface and increases the probability of blockage. Moreover, negatively correlated $\phi_{0}$ and $f_{c 0}$ are more likely to cause blockage.

\section{References}

1. Bonelli, S., Marot, D.: On the modelling of internal soil erosion. In: The 12th International Conference of International Association for Computer Methods and Advances in Geomechanics (IACMAG), 7p (2008)

2. Chang, C.S., Yin, Z.-Y.: Micromechanical modeling for behavior of silty sand with influence of fine content. Int. J. Solids Struct. 48, 2655-2667 (2011)

3. Yin, Z.-Y., Zhao, J., Hicher, P.-Y.: A micromechanics-based model for sand-silt mixtures. Int. J. Solids Struct. 51, 1350-1363 (2014)

4. Yin, Z.-Y., Huang, H.-W., Hicher, P.-Y.: Elastoplastic modeling of sand-silt mixtures. Soils Found. 56, 520-532 (2016)

5. Reddi, L.N., Lee, I.-M., Bonala, M.V.: Comparison of internal and surface erosion using flow pump tests on a sand-kaolinite mixture. Geotech. Test. J. 23, 116-122 (2000)

6. Sterpi, D.: Effects of the erosion and transport of fine particles due to seepage flow. Int. J. Geomech. 3, 111-122 (2003) 